\title{
OBSERVATIONS ON THE EFFECT OF STORM PHENOMENA ON INSECT ACTIVITY'
}

\section{By D. C. Parman, United States Bureau of Entomology}

The discussion will deal primarily with the effect of barometric pressure on insect life as other storm phenomena-wind, rainfall, temperature, atmospheric moisture, etc., - -have been more fully studied and discussed in general literature and time and space will not allow more than brief reference to these to make the matter clear. No experimental data have been gathered, all observations being made in natural surroundings and in cages used in other experimental work. Most of the observations have been made on Muscids and related diptera, only general notes being made on other insects in the field and at lights.

Until the fall of 1916 no barometer was available at the Uvalde, Texas, laboratory where the observations recorded herein were made. This permitted only of studies of the daily map of the Weather Bureau in connection with records made on insect activities. In the fall of 1916 a compensating aneroid barometer was obtained and since that time regular readings have been made at 8:00 a. m. and 8:00 p. m. with special readings at time of storms.

The first observation made on a storm of any severity was on the West Indian hurricane which passed over southwest Texas on the night of August 18, 1916. Some of the more significant data relating to this storm will be given from an extract of the "Monthly Weather Review" of August, 1916, and this publication should be consulted for fuller details. "The tropical cyclone passed inland between Corpus Christi and Brownsville the afternoon and evening of the 18th. After passing inland a short distance south of Corpus Christi the cyclone continued to move in a west-northwest direction, reaching Del Rio, Texas, at about 7:30 a. m. local mean time August 19, with a minimum pressure of 28.69 inches. Since it passed Corpus Christi, 200 miles distant, 12 hours earlier, we may assign a movement of about 17 miles per hour. The recovery of the pressure after the passage of the center of the storm was extremely rapid. . . . We must consider that it dissipated over southwest Texas during the daylight hours of the 19th. . . . It is worthy of note that all of the tropical cyclones of August, 1916, were characterized by remarkably small diameters and naturally extremely steep barometric gradients near the center only. . . . And the fact that the centers did not closely approach any of the network of land stations except for a very brief period, the location of the center of the storms in each case was a very unsatisfactory matter . . (Corpus Christi). The barometer reached its lowest point,

\footnotetext{
${ }^{1}$ Published with the permission of the Chief of the Bureau of Entomology.
} 
29.05-29.07 inches reduced to sea level at $6: 15 \mathrm{p.} \mathrm{m}$. . . . The wind . . estimated maximum velocity of 90 miles. . . There can be no question that the storm was a fully developed hurricane with a central pressure at least one inch lower than observed at Corpus Christi."

The following table gives data at different stations.

\begin{tabular}{l|l|c|c|c|c|c}
\hline \hline Date & Place & Minimum pressure1 & Maximum wind velocity & Rainfall \\
\hline 1916 & Hour & Inches & Hour & Miles per hour & Inches \\
\hline $\begin{array}{l}\text { Aug. } \\
18\end{array}$ & Corpus Christi & $6: 15 \mathrm{p} . \mathrm{m}$. & 29.07 & $6: 50 \mathrm{p.m}$. & 90 & 1.58 \\
\hline 18 & Brownsville & $7: 00 \mathrm{p.m}$. & $29.50:$ & $8: 30 \mathrm{p.m}$ & $60^{2}$ & \\
\hline 19 & San Antonio & $1: 00 \mathrm{a} . \mathrm{m}$. & 29.63 & $2: 31 \mathrm{a.m}$. & 56 \\
\hline 19 & Del Rio & & 28.69 & & 60 & \\
\hline
\end{tabular}

1 Reduced to sen level

2 Lowest reading on record for month.

5 min. period.

Judging from the storm damage it must have had its center in the vicinity of Uvalde, Texas, the damage being less both north and south. The rainfall at Uvalde was 3.1 inches and the wind was probably about 75 miles per hour. Not a single windmill was left standing, many small buildings were wrecked and doors and windows were blown from the most substantial houses in the immediate vicinity of Uvalde, the path being in a southeast to northwest direction.

August 18, 1916 was a pleasant summer day about three degrees cooler than the several preceding days, a maximum of 90 and a minimum of 71. The wind was blowing a light breeze from the northeast instead of the usual southeast breeze at this time of the year. No barometer was at hand and no warning of the storm was had except the clustering of the flies. Nothing unusual was noted until about 8:00 p. m., the wind changed to the northwest and became stronger until it was blowing a gale at 2:00 a. m. From 2:00 a. m. to 3:00 a. m. it was changeable and gusty. Probably a little before 3:00 a. m. straight winds from the southeast began to blow and buildings and trees began to fall.

Previous to the storm, only a few days, Stomoxys calcitrans were very abundant and annoying the stock much in the farming districts east of town. After the storm stockmen and farmers made the assertions that the flies were very bad the day before the storm but they had seen very few since. Examinations of certain stock were made eleven days before the storm and they were almost covered with stable flies, while after the storm no individual animal had more than five or six 
flies upon it. At the laboratory, where from one to more than five thousand Musca domestica and Chrysomyia macellaria were taken in periods of 48 hours in traps before the storm only 8 to 31 were taken after the storm during the remainder of the season (trappings were made semi-monthly on 1st and 15th). About 5:00 p. m., August 18, attention was drawn to large numbers of house flies on the screens about the house; many of the screens being literally covered and they were found to be collecting in protected places. A bucket of kitchen refuse was examined where only a few hours before hundreds of $C$. macellaria and $M$. domestica were feeding and only a few specimens of $C$. macellaria were found deep in the bucket and no $M$. domestica were present. After the storm it was rare to see more than two or three specimens of either species for a period of ten to fifteen days. All species of diptera diminished appreciably with the storm, but of the ones under observation Lucilia sp. was least affected.

During the last three years observations have been made on several species of Muscids showing that with a rapidly falling barometer they first become nervously active and then go into a state of partial coma. Some species have a tendency to seek a place of protection at this time, others show this tendency very little but become quiet at a most convenient place. While the flies are in this state of coma they are more subject to action of other destructive agencies, probably diseases included. Heavy rains are destructive to insect life to some extent, as has been observed by other writers and workers. The chilling effect during the storm might have contributed to some extent to the destruction of the flies as the minimum for August 19 was 67 degrees. Mechanical action of the wind and action of sea spray possibly contributed to the destruction, but it is evident that the destruction of flies during this storm was rather unusual and the unusual characteristic of the storm was the very steep and short barometric gradient.

Another tropical storm visited this section September 14 and 15, 1919. This storm was very similar to the storm of August 18, 1916, except the barometric gradient was not so steep and the wind was not quite as strong but lasted longer. The barometer began to fall on the evening of September 13 from 29.05. It was 28.85 on the morning of the 14th and 28.65 in the evening, $10: 00$ p. m. 28.60, 11:00 p. m. 28.55, September 15 at $1: 30$ a. m. 28.45, 2 a. m. 28.50, 3:30 a. m. 28.40, 4:00 a. m. 28.50, 5:00 a. m. 28.45, 6:00 a. m. 28.50, 8: 00 a. m. 28.50, noon $28.70,8: 00$ p. m. 28.90. The rainfall was 3.75 inches. The wind was blowing a strong breeze from the northeast on the morning of the 14th and increased to a high wind by 10:00 p. m. and to the proportions of a storm by 2 a. $\mathrm{m}$. September 15, at which time it became changeable to the southeast and blew from 50 to 60 miles an hour until 
about 4:00 a. m. and probably was blowing 40 miles at $6: 00$ a. m., and a strong wind was blowing at $2: 00 \mathrm{p} . \mathrm{m}$. and a moderate breeze at $8: 00 \mathrm{p} . \mathrm{m}$. The maximum temperature of the 13 th was 91 , the minimum 70 ; 14th, 80 maximum, 72 minimum; 15th, 80 maximum and 67 minimum.

The decrease in the number of flies was quite appreciable after this storm; the abundance of flies before the storm was about the same as before the storm of 1916 except Haematobia irritans which was very numerous prior to the late storm and was not abundant before the storm of 1916. This fly was practically exterminated during the recent storm, adult $C$. macellaria decreased about 75 per cent, $M$. domestica decreased about 50 per cent and Stomoxys calcitrans about 25 per cent. Adults of all species under observation were decreased to some extent. After the storm of 1916 there was never any appreciable increase in the number of adult flies, although weather conditions were apparently very favorable for increase. After the recent storm the increase in all species was rapid. This increase became noticeable about 15 days after the storm, this being approximately the duration of the immature stages of the species concerned. It is quite probable that many of the immature stages as well as the adult flies were killed during the storms. This is caused by the washing and drowning of the larva, as was noted in the last storm and may possibly be augmented by sea spray. It has bcen determined in preliminary experiments that a solution of sodium chloride as weak as .25 per cent is detrimental to breeding of some species of Diptera in certain cases. This destruction of larvæ and pupæ, together with the almost complete destruction of adults during the first storm, left a very few flies to breed and this together with the variable barometric pressures and storms never allowed an increase that was noticeable during 1916. The larger percentage of adults and the more uniform barometric pressure allowed maximum breeding after the 1919 storm.

A typical observation on the reaction of adult flies to barometric pressure was made on November 21, 1916. Several hundred Lucilia sericata and C. macellaria were in a cage at the laboratory and under observation. They became very active from 9:00 a. m. to noon and during this time the temperature increased from 66 to 75 , the humidity fell from 87 to 60 per cent, the wind was blowing a light breeze from the northeast, the barometer rose from 29.05 to 29.15 , at $2: 00 \mathrm{p}$. m. the temperature was 74 , humidity 56 , the wind a light breeze and a little more from toward the east, the barometer was 28.95 inches, the flies were all quiet and most of the Lucilia were in hiding. The day was clear except for a few medium cumulus clouds clearing toward evening. The barometer fell slightly until 6:00 p. m., when it began to rise and the wind changed to the northwest blowing in a strong norther. 
The following observation gives some light on the effect of barometric pressure on the death rate of adult $C$. macellaria, showing that the adults apparently will not chill and die under the effect of a rising barometer as under a lowering barometric pressure. The adults under observation on November 24 were taken in the open and put in a cage November 20 and 22, a total of 366 . The adults under observation November 27 were taken under the same conditions November 25 and 26 , a total of 500 . Between noon and about two o'clock on each date observations and counts were made of the dead flies on the floor of a cloth cage $2 \mathrm{ft}$. cube with board bottom, this cage being inside of a $6 \mathrm{ft}$. cube cage made of screen wire. November 24 , the first cage contained 87 flies alive and 279 dead flies. Nov. 27, 83 dead flies were taken from the second cage and the others became active in a warm room. Thus showing a 76.2 per cent mortality in the first case under a falling barometer as compared with a 16.6 per cent mortality in the second under a rising barometer. It is believed that other conditions could not have caused this wide difference in mortality. The following table gives the weather conditions under which the observations were made:

\begin{tabular}{l|c|c|c|c|c|c}
\hline \hline 1919 & \multicolumn{2}{|c|}{ Temperature } & \multicolumn{2}{c|}{ Barometer } & \multicolumn{2}{c}{ Humidity } \\
\hline Datr & Maximum & Minimum & $8: 00$ A. M. & $8: 00$ P. M. & Maximum & Minimum \\
\hline Nov. & 75 & 61 & 29.45 & 29.15 & 93 & 65 \\
\hline 23 & 70 & 55 & 29.05 & 28.90 & 98 & 87 \\
\hline 24 & 79 & 48 & 29.05 & 2900 & 87 & 36 \\
\hline 26 & 54 & 48 & 29.25 & 20.35 & 98 & 86 \\
\hline
\end{tabular}

Observations made at lights and at room windows at nights indicate that insects attracted to lights are more active during high barometric periods and especially while the barometer is rising. No specific determinations have been made to indicate the relative degree of reaction of different species under any particular condition.

Bred adult Diptera tend to emerge on periods of rising barometer, the heavy emergences apparently always have been during high barometer. Trappings and observations indicate that Muscoid diptera are most abundant during long periods with slight variations in barometric pressure, provided, of course, temperature, humidity and rainfall are favorable.

Migration of Lybithea bachmanni was observed during the summer and fall of 1916 to take place after storms which indicates that the flights were during high barometric pressure. 